\title{
A window to the ideal self: A study of UK Twitter and Chinese Sina Weibo selfie-takers and the implications for marketers
}

\author{
Jenny Weichen $\mathrm{Ma}^{\mathrm{a}, *}$, Yusheng Yang ${ }^{\mathrm{b}}$, Jonathan A.J. Wilson ${ }^{\mathrm{c}}$ \\ a Greenwich Business School, University of Greenwich, Old Royal Naval College, Park Row, Greenwich, London SE10 9LS, UK \\ ${ }^{\mathrm{b}}$ Worcester Business School, University of Worcester, Castle Street, WR1 3AS Worcester, UK \\ ${ }^{c}$ Richmond American University London, 16 Young Street, Kensington, London W8 5EH, UK
}

\section{A R T I C L E I N F O}

\section{Article history:}

Received 1 August 2016

Accepted 1 October 2016

Available online 15 December 2016

\section{Keywords:}

Selfies

Cultural differences

Consumer studies

Social media

Chinese consumers

Marketing communications

\begin{abstract}
A B S T R A C T
The "selfie" is a global social phenomenon - and little work has been done by marketers to understand the mindset of selfie-takers; not to mention the potential to develop selfies as vehicles for new immersive, contextual, and real-time marketing communication channels. Furthermore, marketing literature offers little insight regarding the interpretation of the style, artifacts, location, usage, participants' image, and cultural differences in these pictures. The present study tackles these areas - analyzing cross-cultural data from a total of 344 selfie photos from Twitter and Sina Weibo. Empirical evidence brings insight into the selfie phenomenon in general and drills down further to surface cultural differences between UK and Chinese consumers. Results show that selfie-takers attempt to present an 'ideal self; and secondly the criteria for judging this differ between UK and Chinese consumers - affected by their respective individualistic and collectivist cultures. Study findings confirm that smartphone camera technology usage is a global trend; and interestingly has encouraged a behavioral phenomenon of using selfies to actualize aspirations for perfection. However, the symbolic meanings and social capital derived from selfies are culturally nuanced.
\end{abstract}

(c) 2016 Elsevier Inc. All rights reserved.

\section{Introduction}

"Selfie," the word of 2013 according to the Oxford Dictionary, refers to "a self-portrait photography of oneself (or oneself with other people), taken with a camera or a camera phone held at arm's length or pointed at a mirror, which is usually shared through social media" (Sorokowski et al., 2015). In 2014, Google reported 93 million selfies per day on the Android system alone, indicating the selfies' significant role in the era of Big Data (Brandt, 2014, cited in Senft \& Baym, 2015). This evidence suggests considerable benefits of monitoring consumers' selfies for marketing purposes.

According to the Wall Street Journal (2014), companies have software for scanning individual selfies as part of the big data marketing. Picture analysis offers potential to predict consumer emotion, product usage, and lifestyle from an individual's selfie. To date, little empirical evidence supports the value of the information marketers' gain from monitoring consumer selfies. While taking 'selfies' continues to be a trending topic for marketers and consumer researchers, how selfies contribute to understanding consumer behavior remains unclear.

\footnotetext{
* Corresponding author.

E-mail addresses: w.ma@greenwich.ac.uk (J.W. Ma), yany1_15@uni.worc.ac.uk (Y. Yang), wilsonj@richmond.ac.uk (J.A.J. Wilson).
}

This study provides empirical evidence on consumer selfies from China and the UK. Results provide new insights on what researchers and practitioners can learn from analyzing consumer selfies. This study's contribution is not only exploratory in nature, but the results also provide evidence that cultural differences exist in selfies.

\section{Theoretical background}

\subsection{Selfie as the new form of self-presentation}

Goffman's (1959) self-presentation theory, states that interactions between people can be seen as impression management. People present the positive aspects of self to make the best possible impression on others. Belk's “extended self” (Belk, 1988) argues that a person's possessions comprising the extended self often serve as cues for others to form impressions. Arguably, the selfie is a form of self-presentation. The visual evidence of self, fast-pace, and wide distribution through Social Networking Sites (SNS) makes selfies significantly different from other forms of self-portraits (Frosh, 2015). In other words, selfie serves as a rapid tool for impression management. Self-portraits show viewers a controlled view of the ideal self.

The marketing literature offers scant evidence to explain this relatively new social phenomenon. On the other hand, researchers examine other online self-presentation in great detail. For instance, researchers 
find evidence of consumers creating dating profile to reflect their ideal self through providing deceptive information in their profiles (Ellison, Heino, \& Gibbs, 2006; Toma, Hancock, \& Ellison, 2008). Recently, researchers report that $50 \%$ of Facebook posts are self-enhancement presentations and women use more profile pictures for such selfenhancement behavior (Bareket-Bojmel, Moran, \& Shahar, 2016). Researchers examining the selfie behavior conclude two basic social needs that drive people to use SNS - the need to belong and the need for self-presentation (Nadkarni \& Hofmann, 2012).

Prior studies examine the motivation to take a selfie and the natural drive of social needs. Selfie research tends to focus on individual differences regarding selfies, especially individual personality traits. For instance, studies on selfie posting behavior demonstrate a link to extraversion and narcissism (Weiser, 2015; Sorokowska, Oleszkiewicz, Frackowiak, \& Pisanski, 2016). Another research stream examines individuals' facial expression (e.g. duckface) as an indicator for personality type (Qiu, Lu, Yang, Qu, \& Zhu, 2015). Qiu et al. (2015) develop their selfie coding scheme and find that except for facial expressions (e.g., duckface or pressed lips), an individual's emotions, location information, and whether or not the picture is edited with Photoshop serve as useful variables for selfie analysis. They also find that these cues are personality-related. For example, duckface links to neuroticism, and private location suggest that the individual is less conscientious. These prior studies offer useful insights on what information a selfie can provide.

\subsection{Self-presentation and culture}

While members of individualist cultures tend to be more self-reliant, members from collectivist cultures value group achievement and harmony over individual success (Hofstede, 1980). Following this line of thinking, studies on collectivist cultures document lower self-enhancement levels (Kurman, 2003). However, Goffman's (1959) self-presentation theory notes a distinguishable difference between "frontstage" and "backstage" behaviors of self, suggesting that the way that individuals present themselves depends on whether they are in public or private settings. When one is on stage (in public), a person emphasizes the positive aspects of self.

As the selfies' purpose is mass public distribution, members of collectivist cultures likely exhibit frontstage behavior. Following Goffman (1959), Eckhardt and Houston (1998) report that most consumption activities in China display frontstage behavior. In other words, consumption activities in China primarily are symbolic. This finding implies that selfies, as a form of self-presentation, likely have a stronger symbolic meaning for Chinese consumers than people from highly individualistic cultures. Researchers also argue that positive self-presentation might be more common in some cultures, and further research should investigate culture's role in online self-presentation (Bareket-Bojmel et al., 2016). For example, Kim and Papacharissi (2003) investigate whether or not a cultural difference exists in how people present their personal webpage. While the U.S. samples present themselves in a direct and personal manner, Korean web pages resented the online self by providing interlinks to special interests and were more likely to use manipulated graphics. However, scant evidence examines cross-cultural comparison of selfies.

While the selfie has become significant, the current selfie literature has not yet to comprehensively discuss the phenomenon in the context of marketing literature. The current understanding about selfies (e.g., a means for individuals to show-off; primarily young people do) may not be accurate. At a minimum, assumptions regarding selfies need support by empirical and systematic data before they merit consideration for marketing planning. Practitioners argue that "a selfie that has a "look at me" message differs from a "look at me here or with this item of significance to me" selfie" - brands need to understand this difference (The Guardian, 2015). Another knowledge gap comes from cultural differences. The literature suggests that self-presentation varies in different cultural contexts. Since the selfie is now a common form of self- presentation, an individual's cultural background may influence how people present selfies. Therefore, this study aims to enhance understanding of selfies by collecting cross-cultural data and reporting the marketing implications.

\section{Methods}

The data were collected on Twitter and Sina Weibo (China's most popular microblogging website similar to Twitter). The researchers collected a total of 420 selfies from Twitter and Sina Weibo users (210 selfies each). After excluding photos which cannot be determined as a selfie or not, the total sample was reduced to 344, consisting of $206 \mathrm{fe}-$ males and 138 males (207 from Weibo and 137 from Twitter).

To collect the public data, the researcher used “selfie' (or “自拍”, selfie in Chinese) as the search term and downloaded the link for the first 20 selfies shown in both Twitter and Sina Weibo from 20:00 to 22:00 in UK and China time separately. The data collection procedure lasted for seven days. To code the selfies, picture coding cues (see Appendix A) from past research were employed (Qiu et al., 2015).

1. Selfie location ( $1=$ private place such as bedroom, toilet, student accommodation; 2 = public place such as hotel, workplace, shopping mall, campus),

2. Eye looking at the camera $(1=$ looking at the camera, $2=$ not looking at the camera)

3. Photoshop editing ( $1=$ Photoshop edited, $2=$ not Photoshop edited)

4. Affiliation with friends ( $1=$ alone, $2=$ affiliation with friends), collage photos $(1=$ collage photos, $2=$ not collage photos $)$

5. Physical appearance ( $1=$ face, $2=$ body from breast, $3=$ half body, $4=$ whole body)

6. Position in photo $(1=$ central in photo, $2=$ left in photo, $3=$ right in photo),

7. Makeup ( $1=$ makeup, $2=$ no makeup)

8. Emotion ( 1 = positive emotion, $2=$ negative emotion, $3=$ no emotion). Besides these, based on gestures and facial expression, the photos were classified into 'yeah gesture', 'duck face', 'selfie via mirror', 'pout mouth', 'hand position'

9. The objects in the selfies, if any, also were noted.

Content analysis and thematic analysis are both used to complete the data analysis. Crosstab Chi-square tests compared the data crossculturally.

\section{Results}

Table 1 shows the study results. First, the results show significant cultural difference regarding how individuals are presented in their selfies $(p<0.01)$. For the Chinese, $>80 \%$ of the selfies show just the

Table 1

Results.

\begin{tabular}{llll}
\hline & & $\begin{array}{l}\text { Chinese Weibo } \\
(N=207)\end{array}$ & $\begin{array}{l}\text { UK Twitter } \\
(N=137)\end{array}$ \\
\hline Appearance & Face & $16.7 \%$ & $10 \%$ \\
& Above chest & $64.5 \%$ & $51.5 \%$ \\
& Half body & $9.1 \%$ & $26.5 \%$ \\
Make-up & Whole body & $3.8 \%$ & $10.3 \%$ \\
Public location & & $44.9 \%$ & $32.8 \%$ \\
Private location & & $25.2 \%$ & $28.2 \%$ \\
& Bedroom & $32.9 \%$ & $38.5 \%$ \\
& Inside the & $7.2 \%$ & $17.3 \%$ \\
Unknown & car & & $15.4 \%$ \\
location & & 0 & \\
Photo editing & & $41.9 \%$ & $7.7 \%$ \\
\hline
\end{tabular}


face or the upper chest of the photo takers, while almost $40 \%$ of the selfies from Twitter showed one-half or the entire body of the photo takers. This result helps explain the findings regarding location. While no significance difference exists between the two cultures regarding location, the results show that $41.9 \%$ of the Chinese selfies do not reveal any location information. Some Chinese selfie photo takers intentionally hide the location information by using Photoshop to blur backgrounds. Photo editing is another significant cultural difference found in this study $(p<0.01$ ). Nearly $78 \%$ of the Chinese selfies show obvious signs of editing using Photoshop, especially on individuals' appearance, while only about $36 \%$ of the Twitter selfies appear edited. Similarly, a higher percentage of Chinese selfies show people wearing makeup ( $44.9 \%$ vs. $32.8 \%, p<0.05)$.

\section{Discussion}

First, the results suggest that determining location is much more difficult from Chinese selfies. Chinese consumers are more likely to obscure or hide the location in their selfies. This result counters previous literature on cultural differences on self-presentation, as Rui and Stefanone (2013) report that individualist users tend to engage more in protective self-presentation due to higher public self-consciousness. However, this study does not find evidence to support this claim. Rather, the background location's role may be more significant for Chinese consumers. The evidence shows that the background is customized in some cases. This result confirms Eckhardt and Houston (1998), who argue that private locations such as the home are less used for self-presentation purposes in Chinese culture.

The results also show that Chinese selfies are not merely a form of self-presentation, but they also present their "ideal selves." This finding supports several marketing research studies on Chinese consumers. For example, Sun and Wu (2004) argue that Chinese consumers use different products to reflect their ideal selves and to show improvements of their life standard. Zhao and Belk (2007) also note that young Chinese consumers actively post their consumption activities on their blogs (e.g., mall visits or eating out). These activities link to the concept of "extended self" and acquiring material items. The Internet provides a new means or self-extension through posting images of the ideal self (Zhao \& Belk, 2007). Based on this concept, selfies for Chinese consumers more likely serve as their online "avatar," which is the digital representation of self (Wilson \& Liu, 2009).

Belk (2013) suggests that consumers have more choices to customize their self-presentation online with the help of computer software such as Photoshop. Options to modify suggest that one's online avatar represents one's ideal self. This notion also explains why more Chinese selfie participants wear makeup. This finding also implies that previous researchers argue that selfie-posting behavior's relationship to narcissism may not apply in the Chinese context. Rather, Chinese selfie-posting may serve as an attempt to boost self-esteem. This explanation helps explain why previous studies on selfie-posting behavior and narcissism often generate inconclusive results (Sorokowska et al., 2016).

Similar to the concept of the "ideal-self", for the selfies on Twitter, some selfies are taken in bathrooms (e.g., finishing makeup application before going out) while none were found in the Chinese samples. Other common private locations for both cultures included bedrooms $(34.8 \%$ of Chinese and $17.3 \%$ of Twitter users) and inside the cars (7.2\% of Chinese and $15.4 \%$ of Twitter users). These findings suggest that selfie behavior may link to consumer grooming rituals.

Rook (1985) argues that consumer grooming patterns and the using consumer items and brands are consumer rituals, which they adopt in order to create a more ideal self. Moreover, Twitter selfies more commonly convey sex appeal, especially selfies of half or the whole body (e.g., breasts, bottoms, and chest/belly muscle). A cross-cultural study comparing consumer attitudes in Canada, China, and the U.S. on sexual imagery in advertising reveals that Chinese consumers have the least positive attitudes regarding sexual imagery in advertising (Liu, Cheng,
\& Li, 2009). The evidence suggests that the image of being "sexy" has less value to Chinese consumers.

Chinese consumers exhibit what appears to be a more visible manifestation of an ideal self. However, this finding does not imply that UK consumers ignore efforts to achieve the same objective. UK consumers may seek the same result to a lesser degree. Reflecting on the raison d'être for taking a selfie, UK consumers appear more engaged in subtle, inconspicuous and self-effacing behavior to fulfil the same desires. These observations extend prior studies on inconspicuous branded consumption (Eckhardt, Belk, \& Wilson, 2015; Wilson, Eckhardt, \& Belk, 2015), describing a consumer preference for not standing out as ostentatious.

Study results support more tenable position points to selfie-takers expressing a range of social needs, culminating in the portrayal of contextual ideal self and extended-self artifacts. The overtness and conspicuousness of this message are subject to cultural contexts. Therefore, a challenge to marketers is developing an understanding key element in selfies and how to interpret them properly before selfies can be used as a rich data source to unpack the subtle changes in consumer values and behavior.

\section{Conclusion}

This study provides several interesting insights regarding selfies. First, Chinese selfies tend to employ photo editing tools such as Photoshop. The Chinese smartphone brand Huawei actually promotes their smartphone by emphasizing pre-installation of photo editing apps. Presenting the "ideal self" also corresponds to Chinese behavior such as overspending and luxury consumption (Zhao \& Belk, 2007). More importantly, this study provides evidence to marketers and researchers that the selfie, as a form of self-presentation, deserves further investigation with the consideration of cultural context. For example, marketers may not be able to acquire much information regarding selfie location in China.

Although this study provides a better understanding of selfie behavior, findings need to be interpreted with caution. Due to the data collection method, individual background information such as age and socioeconomic status is not available. Demographic information might explain some differences in selfie behavior. Also, since the selfies were collected over a two-hour period during each of the seven days, this snapshot in time may exclude people who are not active on SNS at the selected hours and on the selected days. Future research should address the data collection issue in order to provide more representative findings.

\section{Acknowledgements}

The authors thank Dr. Saad Ali and Mr. Joel Hooper for proof reading and constructive feedback.

Appendix A. Coding scheme.

\begin{tabular}{|c|c|}
\hline Selfie location & $\begin{array}{l}\text { 1. Private place: Bedroom, toilet, student } \\
\text { accommodations } \\
\text { 2. Public place: Hotel, workplace, shopping mall, } \\
\text { campus }\end{array}$ \\
\hline $\begin{array}{l}\text { Eye looking at the } \\
\text { camera }\end{array}$ & $\begin{array}{l}\text { 1. Looking at the camera } \\
\text { 2. Not looking at the camera }\end{array}$ \\
\hline Photoshop editing & $\begin{array}{l}\text { 1. Photoshop edited } \\
\text { 2. Not Photoshop edited }\end{array}$ \\
\hline Affiliation with friend & $\begin{array}{l}\text { 1. Along } \\
\text { 2. Affiliation with friends }\end{array}$ \\
\hline Collage photo & $\begin{array}{l}\text { 1. Collage photos } \\
\text { 2. Not collage photos }\end{array}$ \\
\hline
\end{tabular}

(continued on next page) 
(continued)

$\begin{array}{ll}\text { Make up } & \text { 1. With makeup } \\ \text { Gestures } & \text { 2. No makeup } \\ & \text { 1. Yeah gesture } \\ \text { Position in photo } & \text { 2. Other hand positon } \\ & \text { 1. Central in photo } \\ & \text { 2. Left in photo } \\ \text { Emotion } & \text { 3. Right in photo } \\ & \text { 1. Positive emotion } \\ \text { Facial expression } & \text { 2. Negative emotion } \\ & \text { 3. No emotion } \\ & \text { 1. Duck face } \\ \text { Physical appearance } & \text { 3. Pout mouth } \\ & \text { 1. Face facial expression } \\ & \text { 2. Body from breast } \\ & \text { 3. Half body } \\ \text { 4. Whole body }\end{array}$

\section{References}

Bareket-Bojmel, L., Moran, S., \& Shahar, G. (2016). Strategic self-presentation on Facebook: Personal motives and audience response to online behavior. Computers in Human Behavior, 55, 788-795.

Belk (2013). Extended self in a digital world. Journal of Consumer Research, 40(3), $477-500$.

Belk, R. W. (1988). Possessions and the extended self. Journal of Consumer Research, 15(2), 139

Eckhardt, G. M., \& Houston, M. J. (1998). Consumption as self-presentation in a collectivist society. AP-Asia Pacific Advances in Consumer Research, Volume, 3.

Eckhardt, G.M., Belk, R.W. \& Wilson, J.A.J. (2015), "The rise of inconspicuous consumption", Journal of Marketing Management, Vol.21 Iss.7-8. 807-826.

Ellison, N., Heino, R., \& Gibbs, J. L. (2006). Managing impressions online: Self-presentation processes in the online dating environment. Journal of Computer-Mediated Communication, 11, 415-441.

Liu, F., Cheng, H., \& Li, J. (2009). Consumer responses to sex appeal advertising: A crosscultural study. International Marketing Review, 26(4/5), 501-520.

Frosh, P. (2015). The gestural image: The selfie, photography theory, and kinesthetic sociability. International Journal of Communication, 9, 1607-1628.
Goffman, E. (1959). The presentation of self in everyday life. New York: Doubleday.

Hofstede, G. (1980). Culture and organizations, Int. Studies of Man. E Org., X(4), 15-41.

Kim, H., \& Papacharissi, Z. (2003). Cross-cultural differences in online self-presentation: A content analysis of personal Korean and US home pages. Asian Journal of Communication, 13(1), 100-119.

Kurman, J. (2003). Why is self-enhancement low in certain collectivist cultures?: An investigation of two competing explanations. Journal of Cross-Cultural Psychology, 34(5), 496-510.

Nadkarni, A., \& Hofmann, S. G. (2012). Why do people use Facebook? Personality and Individual Differences, 52(3), 243-249.

Qiu, L., Lu, J., Yang, S., Qu, W., \& Zhu, T. (2015). What does your selfie say about you? Computers in Human Behavior [online], 52, 443-449.

Rook, D. W. (1985). The ritual dimension of consumer behavior. Journal of Consumer Research, 12(3), 251-264.

Rui, J., \& Stefanone, M. A. (2013). Strategic self-presentation online: A cross-cultural study. Computers in Human Behavior, 29(1), 110-118.

Senft, T. M., \& Baym, N. K. (2015). What does the selfie say? Investigating a global phenomenon introduction. International Journal of Communication, 9, 1588-1606.

Sorokowski, P., Sorokowska, A., Oleszkiewicz, A., Frackowiak, T., Huk, A., \& Pisanski, K. (2015). Selfie posting behaviors are associated with narcissism among men. Personality and Individual Differences, 85, 123-127.

Sorokowska, A. Oleszkiewicz, A. Frackowiak, T., \& Pisanski, K. (2016). Selfies and personality: Who posts self-portrait photographs? Personality and Individual Differences, 90 119-123.

Sun, T., \& Wu, G. (2004). Consumption patterns of Chinese urban and rural consumers. Journal of Consumer Marketing, 21(4), 245-253.

The Guardian (2015)" Brands should look again at using selfies in their marketing campaigns". Retrieved from http://www.theguardian.com/media-network/2015/may/ 05/brands-selfies-marketing-campaigns

Toma, C. L., Hancock, J. T., \& Ellison, N. B. (2008). Separating fact from fiction: An examination of deceptive self-presentation in online dating profiles. Personality and Socia Psychology Bulletin, 34(8), 1023-1036.

Journal, W. S. (2014). Smile, Marketing Firms are Mining Your Selfies Retrieved from http:// www.wsj.com/articles/smile-marketing-firms-are-mining-your-selfies-1412882222

Weiser, E. B. (2015). \#Me: Narcissism and its facets as predictors of selfie-posting frequency. Personality and Individual Differences [online], 86, 477-481.

Wilson, J. A. J., Eckhardt, G. M., \& Belk, R. W. (2015). Luxury branding below the radar. September: Harvard Business Review, 26-27.

Wilson, J.A.J. \& Liu, J. (2009), “'The Pinocchio effect' - When managing the brand creation process, across cultures", TMC Academic Journal, Vol. 4(1), pp.45-58.

Zhao, X. and Belk, R. W. (2007)."Live from shopping malls: Blogs and Chinese consumer desire", Advances in Consumer Research, 34, 131-137. 